\title{
Онтогенетическая структура ценопопуляции Fragaria viridis Duch. (Rosaceae) на отвале горной породы
}

\section{Ontogenetic structure of Fragaria viridis Duch. (Rosaceae) coenopopulation on the rock dumps}

\author{
Олефиренко И. О. \\ Olefirenko I. O. \\ Кемеровский государственный университет, г. Кемерово, Россия. E-mail: olefirenko.i@yandex.ru
}

Kemerovo State Univercity, Kemerovo, Russia

\begin{abstract}
Peфepam. Впервые для Кемеровской области исследована онтогенетическая структура ценопопуляции $F$. viridis, произрастающей на отвале горной породы. Она нормальная неполночленная, в ней могли отсутствовать старые растения. На затененном участке фитоценоза произрастали растения более молодого возрастного состояния. Онтогенетический спектр определен как левосторонний, не меняющий своего характера из года в год.
\end{abstract}

Ключевые слова. Возрастной спектр, онтогенетическая структура, отвал горной породы, ценопопуляции, Fragaria viridis.

Summary. For the first time in Kemerovo region the ontogenetic structure of $F$. viridis coenopopulation growing on the rock dump was studied. It is normal incomplete, it could be missing old plants. The plants of a younger age grew on the shaded area of the phytocenosis. The ontogenetic spectrum is defined as a left-sided spectrum that does not change its character from year to year.

Key words. Age spectrum, coenopopulations, Fragaria viridis, ontogenetic structure, rock dump.

Кемеровская область является одним из старейших горнодобывающих регионов России, в котором уже многие десятилетия интенсивно развиваются угольная промышленность и металлургия. Вследствие этого повсеместно на ее территории происходит образование промышленных отвалов, отрицательно воздействующих как на здоровье человека, так и на естественные природные комплексы фитоценозы. При постоянном изменении экологической обстановки большое значение имеет изучение внутривидовой изменчивости ценопопуляций, в котором основополагающее место занимает популяционно-онтогенетический подход. Ценопопуляционные исследования вносят вклад в разработку теории экологического мониторинга, позволяют оценить скорость восстановления биоразнообразия на нарушенных промышленностью территориях и разработать способы рационального использования растительных ресурсов и их охраны (Ильина, 2010). Данная работа является продолжением исследований состояния ценопопуляций растений, произрастающих на отвалах горнопромышленных предприятий Кемеровской области (Романова, 2015; Романова, Ажичакова, 2016; Валуева, Романова, 2018; Romanova, Olefirenko, 2018).

Цель работы - изучить возрастную структуру ценопопуляции Fragaria viridis Duch., произрастающей на отвале горной породы.

Fragaria viridis - многолетнее, короткокорневищное, наземностолонообразующее поликарпическое растение семейства Rosaceae (Григорьева, 1995). Распространена в Европе, за исключением Крайнего Севера и южного Средиземноморья, на Урале, в Средней Азии. В Сибири ее ареал простирается до Байкала, восточнее которого она не встречается (Курбатский, 1988).

Для земляники характерны перекрёстное опыление насекомыми и самоопыление. Семена разносятся птицами. Новые популяции возникают за счёт семенного размножения, а их разрастание осу- 
ществляется вегетативно (Машкова и др., 2012). По типу жизненной стратегии $F$. viridis относится к группе растений, сочетающих свойства эксплерентов и ценотических патиентов, для которых характерно увеличение численности и ускорение онтогенеза в нарушенных местообитаниях (Стецук, 2010). Светолюбивое растение, мезофит, мезотроф. Произрастает на остепненных лугах, лесных открытых полянах и опушках, на краю леса, в осиново-березовых колках (Алексеев и др., 1988; Вдовина и др., 2014).

Исследования проводили в окрестностях п. Привольный Кемеровского района в 2016-2018

гг. в первой декаде июля. Исследуемая ценопопуляция $F$. viridis располагалась в нижней части склона южной экспозиции отвала горной породы, в пределах формирующегося разнотравно-злакового сообщества. Отвал состоит из трёх ярусов, отсыпанных в разное время. На верхнем ярусе была проведена биологическая рекультивация, на нижнем и среднем ярусах следов рекультивации не обнаружено (Романова, 2015).

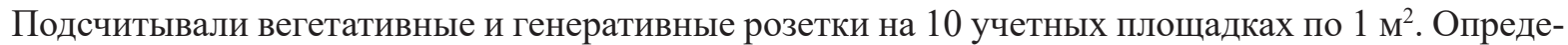
ляли возрастные состояния розеток по Григорьевой Н. М. (1995) и интерпретировали возрастные спектры по Заугольновой Л. Б. с соавторами (Ценопопуляции растений ..., 1988). Изучали онтогенетическую структуру F. viridis на освещённом и затенённом участках фитоценоза, а также в ценопопуляции в целом.

В период исследований ценопопуляция $F$. viridis была представлена двумя зарослями. Первая произрастает на открытом пространстве. На этом участке покрытие фитоценоза в годы исследования

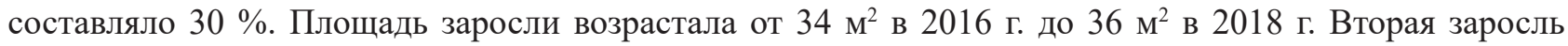
подвергается затенению близ стоящими деревьями, проективное покрытие этой части фитоценоза 60 70 \%. В 2016-2018 гг. ее площадь увеличилась с 5 до 6,5 м².

В 2016 г. в освещённом местообитании (заросль 1) отсутствовали постгенеративные, а на затенённом участке (заросль 2) - старые генеративные и постгенеративные розетки. Возрастной спектр заросли 1 характеризовался как левосторонний, с абсолютным преобладанием зрелых генеративных розеток $(47 \%)$ (рис. $1 \mathrm{~A})$.
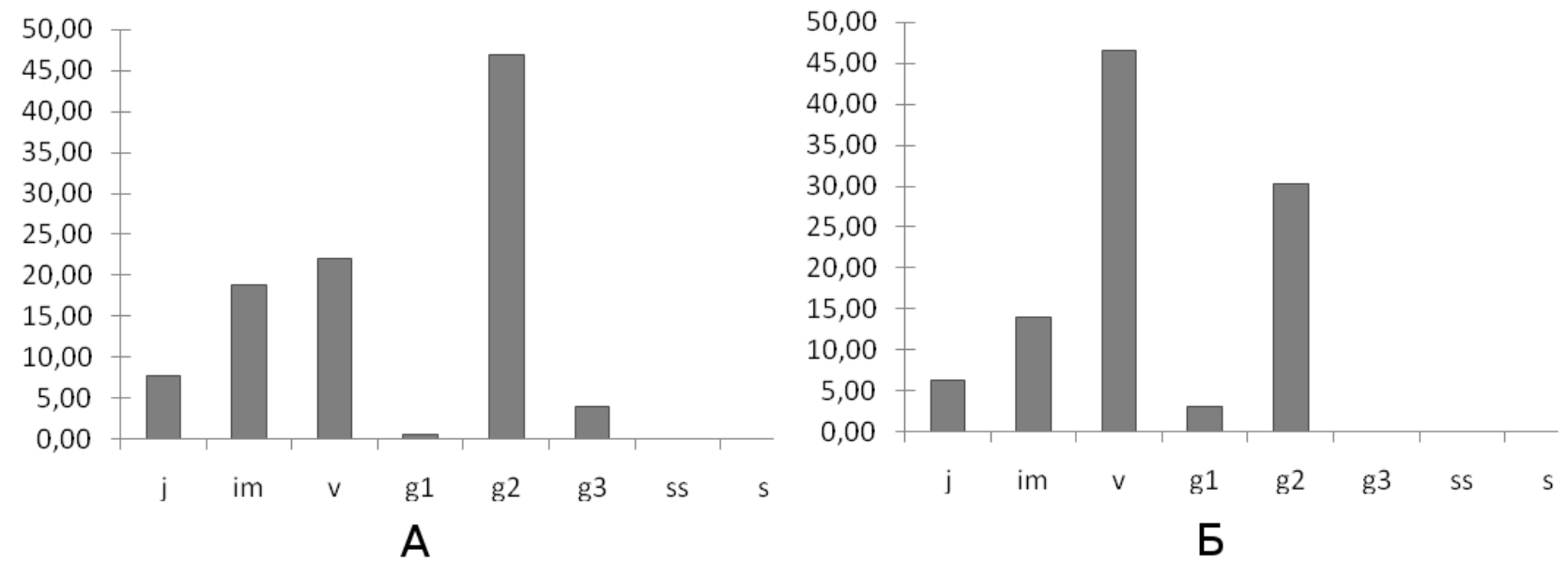

Рис. 1. Возрастные спектры F. viridis для зарослей 1 (А) и 2 (Б) в 2016 году. Условные обозначения: по оси $x$ - возрастные состояния, по оси $y$ - доля особей, \%.

Для возрастного спектра заросли 2 также получен левосторонний спектр, но преобладали виргинильные розетки (47 \%) (рис. 1Б). Большая доля розеток пришлась на зрелые генеративные (30 \%). В данной заросли возрастной спектр з. зелёной приближен к базовому, установленному Григорьевой (1995) для данного вида, где локальный максимум образуют старые растения, а абсолютный максимум чаще приходится на прегенеративные растения. Он подобен полученному Дубровной С. А. и Ведерниковой О. П. (1998) для з. лесной - близкородственного вида - произрастающей на затенённых участках. 
В 2017 г. заросль 1 характеризовалась левосторонним возрастным спектром (рис. 2А), с наибольшими долями виргинильных и средневозрастных генеративных особей (35 и $45 \%$, соответственно). Доля остальных возрастных состояний оказалась незначительной.

В заросли 2 розетки также распределились в левосторонний возрастной спектр, но с ярко выраженным преобладанием особей прегенеративной фракции (около 65 \%) (рис. 2Б). При этом было отмечено наличие зрелых генеративных розеток. В обеих зарослях появились субсенильные розетки.

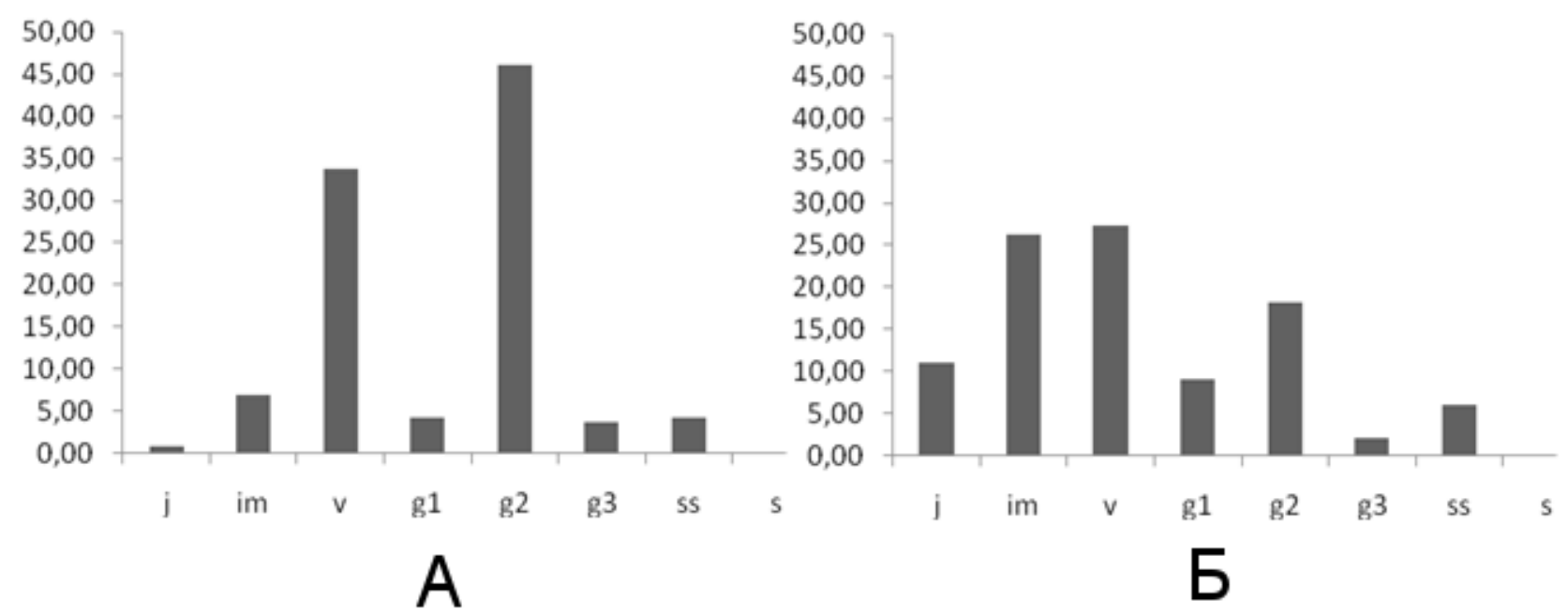

Рис. 2. Возрастные спектры F. viridis для зарослей 1 (А) и 2 (Б) в 2017 году. Условные обозначения те же, что на рис. 1.

В 2018 г. возрастные спектры для обеих зарослей были сходными. В них полностью отсутствовали постгенеративные розетки. В заросли 1 доли виргинильных и средневозрастных генеративных розеток составили 38 и $41 \%$ (рис. 3А), в заросли $2-31$ и $53 \%$ (рис. 3Б).
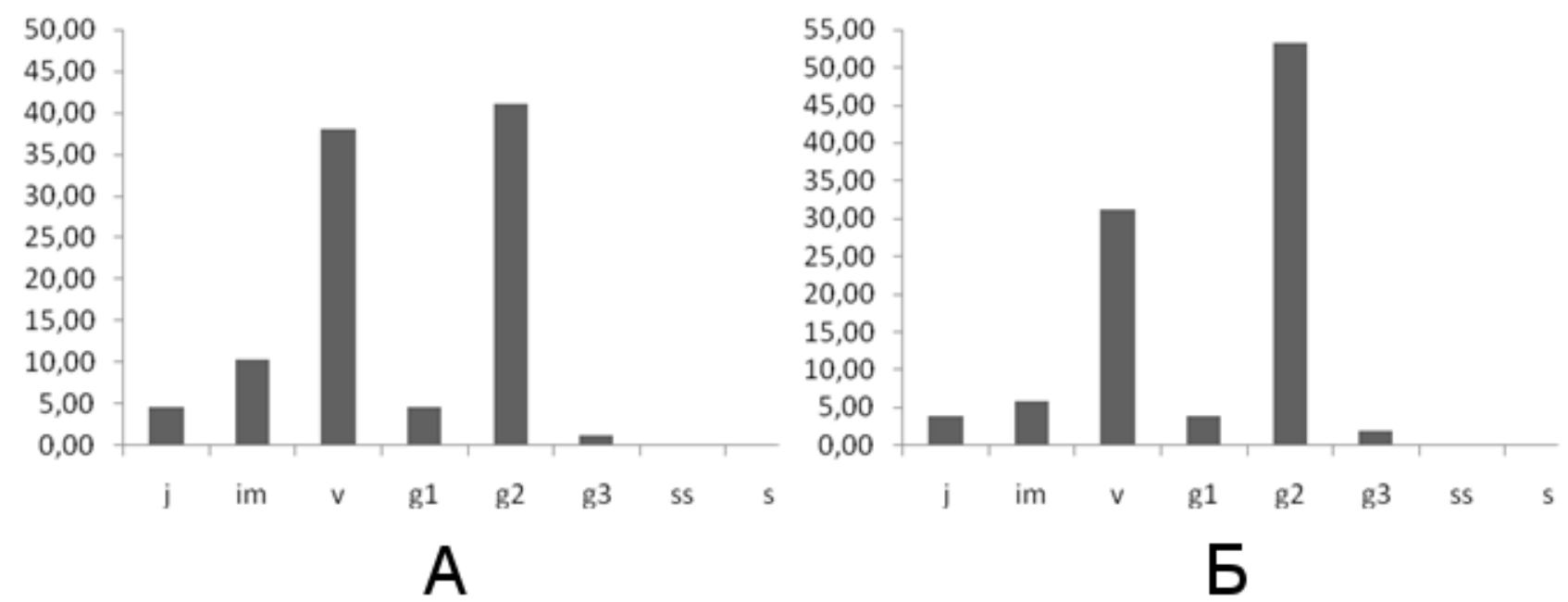

Рис. 3. Возрастные спектры F. viridis для зарослей 1 (А) и 2 (Б) в 2018 году. Условные обозначения те же, что на рис. 1.

Таким образом, анализ динамики возрастных спектров заросли 1 показал, что в годы исследования изменения типа возрастного спектра не происходило: он был левосторонним с абсолютным преобладанием виргинильных и средневозрастных генеративных розеток. Розетки постгенеративного периода (субсенильные) отмечались только в 2017 г. 
Онтогенетический спектр заросли 2 в годы исследования также оставался левосторонним. Преобладали растения виргинильные и средневозрастные генеративные, хотя в 2017 г. высокой оказалась и доля имматурных растений. Старые генеративные и субсенильные розетки отмечали только в 2017 г.

Возрастной спектр исследуемой ценопопуляции в целом представлен на рисунке 4 . На рисунке видно, что из года в год варьировала доля розеток определенного возрастного состояния, но изменения типа возрастного спектра не происходило: он был левосторонним с абсолютным преобладанием виргинильных и средневозрастных генеративных розеток. Полученные нами данные согласуются с ранее описанными в литературе для близкородственного вида в других трансформированных местообитаниях (Дубровная, Ведерникова, 1998).

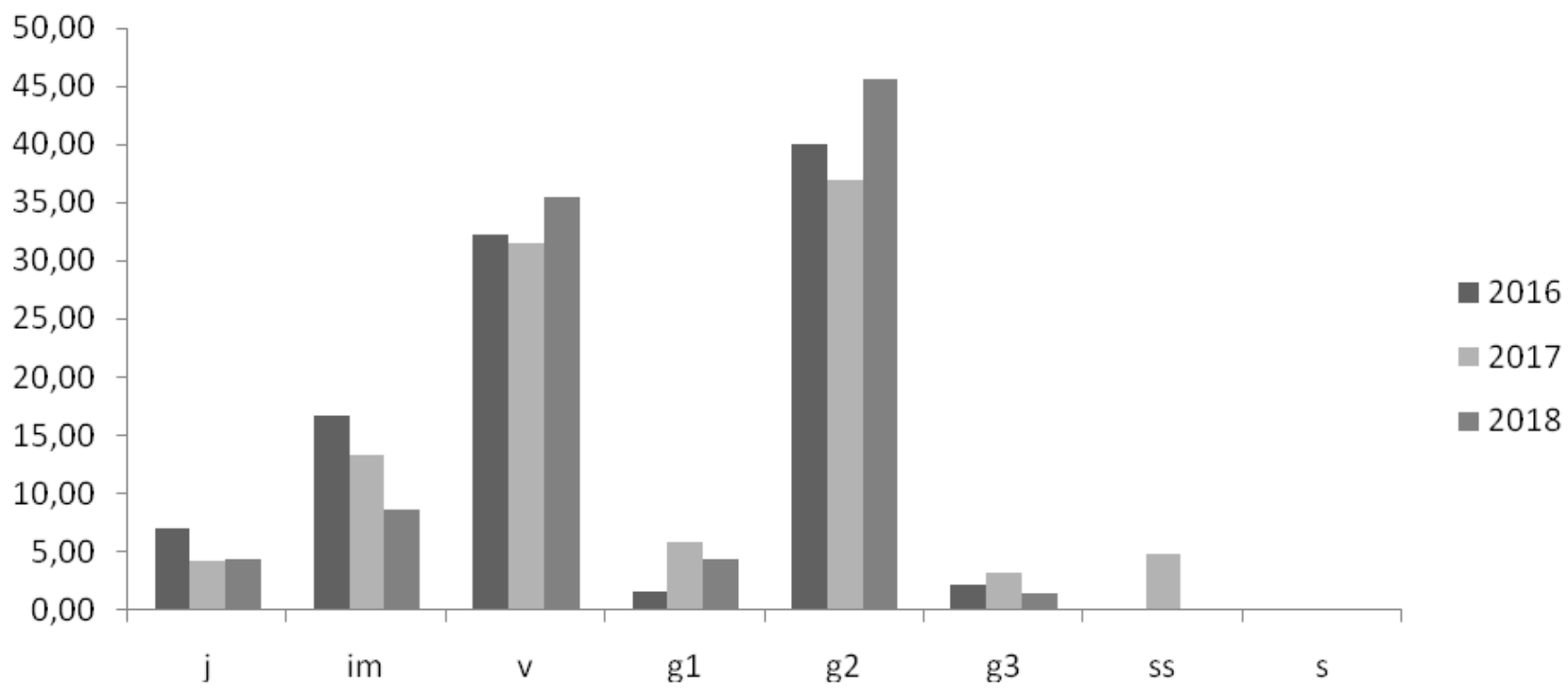

Рис. 4. Возрастной спектр ценопопуляции F. viridis на отвале горной породы, 2016-2018 гг. Условные обозначения те же, что на рис. 1.

Таким образом, в годы исследования ценопопуляция з. зеленой, произрастающая на отвале горной породы, была нормальной неполночленной - в ней могли выпадать растения постгенеративного периода. Часть ценопопуляции, расположенная на теневом участке, содержала розетки более молодого возрастного состояния, чем на освещённом участке. Онтогенетический спектр был левосторонним. Его характер указывает на смешанный тип самоподдержания ценопопуляций $F$. viridis, что соответствует жизненной форме вида.

\section{ЛИТЕРАТУРА}

Алексеев Ю. Е. Лесные травянистые растения. Биология и охрана: справочник. - М.: Агропромиздат, 1988. $223 \mathrm{c}$.

Валуева Д. С., Романова Н. Г. Число и завязываемость семян Fragaria vesca L. (Rosaceae) в зависимости от условий произрастания // Проблемы ботаники Южной Сибири и Монголии: Сб. науч. ст. по материалам XVII междунар. науч.-практ. конф. (24-27 мая 2018 г., Барнаул). - Барнаул: Изд-во АлтГУ, 2018. - С. 184-186.

Вдовина T. А., Серова О. А., Каданцева Н. М. Изучение основных фитоценотических и хозяйственных признаков земляники зеленой Fragaria viridis (Duch.) Weston. в природных условиях (Восточно-Казахстанская область) // European Resercher, 2014. - Т. 84. - № 10-1. - С. 1728-1735.

Григорьева Н. М. Земляника зеленая // Биологическая флора Московской области. - М.: Изд-во МГУ; Изд-во «Аргус», 1995. - Вып. 10. - С. 119-133.

Дубровная С. А., Ведерникова О. П. Возрастная структура ценопопуляций Fragaria vesca L. // Экология и генетика популяций. - Йошкар-Ола: Периодика Марий Эл, 1998. - С. 220-222. 
Ильина В. Н. Исследования ценотических популяций растений (фитоценопопуляций) в Самарской области // Самарская Лука: проблемы региональной и глобальной экологии. - Самара, 2010. - С. 99-104.

Курбатский В. И. Fragaria L. - Земляника // Флора Сибири. Rosaceae. - Новосибирск: Наука, 1988. - С. 34-35.

Машкова A. А., Докучаева Ю. А., Избасарова $\boldsymbol{C}$. C. О влиянии экологических факторов на генеративную активность Fragaria viridis (Duch) Weston степной зоны Оренбурского предуралья // Приволжский науч. вестник, 2012. - № 1 (5). - C. 3-6.

Романова Н. Г. Структура ценопопуляций Fragaria vesca L. в различных местообитаниях // Проблемы ботаники Южной Сибири и Монголии: Сб. науч. ст. по материалам XIV междунар. науч.-практ. конф. (Барнаул, 25-29 мая 2015 г.). - Барнаул: Изд-во АлтГУ, 2015. - С. 291-294.

Романова Н. Г., Ажичакова $\boldsymbol{E}$. C. Особенности возрастной структуры ценопопуляций Fragaria vesca L. в техногенном ландшафте // Флора и растительность Сибири и Дальнего Востока: Чтения памяти Л. М. Черепнина и VI Всероссийская конф. с междунар. участием, посвящ. 110-летию со дня рождения Л. М. Черепнина и 80-летию Гербария им. Л. М. Черепнина (KRAS). - Красноярск, 2016. - С. 302-307.

Стецук Н. П. Экологические особенности Platanthera bifolia (L.) Rich. на территории Южного Приуралья // Вестник ОГУ, 2010. - № 6 (112). - С. 34-37. $184 \mathrm{c}$.

Ценопопуляции растений (очерки популяционной биологии) / Л. Б. Заугольнова [и др.]. - М.: Наука, 1988. -

Romanova N., Olefirenko I. Age structure of coenopopulation of Fragaria vesca L. in the natural and transformed habitats // BIO Web Conf., 2018. - V. 11. - URL: https://www.bio-conferences.org/articles/bioconf/full_html/2018/02/ bioconf_pdcmb2018_00035/bioconf_pdcmb2018_00035.html 